\title{
Photoperiod, Carbon Partitioning, and Reproductive Development in Rabbiteye Blueberry
}

\author{
Rebecca L. Darnell \\ Department of Fruit Crops, University of Florida, Gainesville, FL 32611 \\ Additional index words. Vaccinium ashei, daylength, flower bud initiation
}

\begin{abstract}
Containerized 'Climax' and 'Beckyblue' rabbiteye blueberry plants (Vaccinium ashei Reade) were exposed to 5 weeks of natural daylengths or shortened daylengths starting 30 Sept. 'Beckyblue' plants exposed to short daylengths in the fall initiated more flower buds and had a shorter, more concentrated bloom period than did plants exposed to natural fall daylengths. Reproductive development of 'Climax' was not influenced by photoperiod treatments. Leaf carbon assimilation of both cultivars increased under short days. Partitioning of translocated ${ }^{14} \mathrm{C}$-labeled assimilates to stem tissue increased under short photoperiods for 'Beckyblue'; however, partitioning patterns in 'Climax' were not affected. Increased carbon fixation and increased partitioning of carbon to stem tissue under short days may contribute to the observed effect of short days on enhancing reproductive development in 'Beckyblue'.
\end{abstract}

Flower bud initiation in highbush and lowbush blueberry is promoted under short days. Aalders and Hall (1964) and Hall and Ludwig (1961) reported that, in general, initiation in lowbush blueberries required photoperiods $<12 \mathrm{~h}$. There was clonal variation, however, with some clones able to produce flower buds at 14 and $16 \mathrm{~h}$, although the number of flower buds produced usually was not as high (Hall and Ludwig, 1961). At least 5 to 6 weeks of the required photoperiod were needed for normal flower bud initiation. There was a decrease in shoot growth concomitant with an increase in flower bud production.

The photoperiod response of highbush blueberries is similar to lowbush. Eight weeks of 8-, 10-, or 12-h photoperiods resulted in flower bud initiation in highbush cultivars, whereas fewer flower buds were formed under 14- and 16-h photoperiods (Hall et al., 1963). Vegetative growth was highest under 16-h photoperiods and least under $8 \mathrm{~h}$. Maximum flower bud initiation occurred under 10 -h photoperiods and was attributed to the more extensive shoot growth produced under a 10-h than under an 8 -h photoperiod, providing more shoots on which to produce flower buds.

Photoperiod effects in rabbiteye blueberries, the major blueberry species grown in the southeastern United States, have not been documented. Defoliating shoots of field-grown 'Aliceblue' plants in late August or mid-September in Florida markedly decreased flower bud initiation on those shoots (P. Lyrene, unpublished data). Partial defoliation, where every other leaf was removed, also decreased initiation, although not as dramatically. In general, flower bud initiation was localized at those nodes that still retained leaves. It is unclear from this work whether the reduction in flower bud initiation due to premature defoliation was due directly to a localized carbohydrate limitation or to a photoperiod effect, which in turn may affect flower bud initiation via a hormonal or photosynthate allocation signal (Abou-Haidar et al., 1985; Bodson, 1977; Ogawa and King, 1979).

The influence of photoperiod on flower bud initiation and other reproductive responses in rabbiteye blueberry may be a determining factor in the continued southward expansion of the industry and in selection of breeding strategies toward this end. New cultivars with lower chilling requirements are being developed for areas of relatively low latitude where fall photo-

Received for publication 14 Dec. 1990. Univ. of Florida Journal Series no. R-01495. The cost of publishing this paper was defrayed in part by the payment of page charges. Under postal regulations, this paper therefore must be hereby marked advertisement solely to indicate this fact. periods may be too long for optimum flower bud initiation. The purpose of the present study was to determine the effects of shortened fall photoperiods on flower bud initiation in rabbiteye blueberry. Additionally, photoperiod effects on photosynthate production and allocation in rabbiteye blueberry were examined to determine if photoperiodically induced changes in these processes may contribute to observed differences in flower bud initiation.

\section{Materials and Methods}

Photoperiod treatments. Two-year-old 'Climax' and 'Beckyblue' rabbiteye blueberry plants growing in 22-liter plastic pots containing peat were selected for the experiment. Starting 30 Sept. 1988, 16 plants of each cultivar were assigned to either the natural photoperiod (i.e., gradually decreasing daylengths from 12 to $11 \mathrm{~h}$ ) or a short-day photoperiod (i.e., 5 days at 10 $\mathrm{h}$, followed by 5 days at $9 \mathrm{~h}$, followed by 30 days at $8 \mathrm{~h}$ ), each of which lasted 40 days. Plants were grown outdoors on gravel beds in Gainesville, Fla. Short days were implemented by covering plants at night with large A-frame structures rendered lighttight by layers of black plastic and with an outer layer of black cloth that was painted white to reflect sunlight. Exposure of Polaroid Polacolor 669 ASA 80 film for $90 \mathrm{sec}$ under the Aframe during daylight hours indicated that complete darkness was achieved. The structures were removed at appropriate times in the early morning, depending on the specific photoperiod schedule. Two plants of each cultivar were placed under each of the four structures, which were randomly arranged in a gravel bed. Two control plants of each cultivar remained under natural photoperiods immediately adjacent to each of the structures, giving four replications and two subsamples per replication. Thermograph readings under the structures indicated that the maximum temperature increase compared to ambient air was $<4 \mathrm{C}$, and generally $<2 \mathrm{C}$, throughout the course of the experiment. There were no apparent differences in water use between plants in the two photoperiod treatments; all plants were watered daily.

On 8 Nov., all plants were hand-defoliated and placed in a darkened chamber at $7 \mathrm{C}$ for $900 \mathrm{~h}$ before transfer to a greenhouse. The average maximum and minimum in the greenhouse was $33 \pm 2 \mathrm{C}$ and $18 \pm 3 \mathrm{C}$, respectively. Midday photosynthetic photon flux (PPF) ranged from 300 to $1290 \mathrm{~mol} \cdot \mathrm{m}^{-2} \cdot \mathrm{s}^{-1}$, depending on the extent of cloud cover. The rate and amount of floral and vegetative budbreak were determined from 27 Dec. to 27 Mar. Final fruit set and fruit weight were determined at harvest. The experiment was repeated in 1989. 
Photosynthate production and allocation. In $1989, \mathrm{CO}_{2}$ assimilation (A), leaf carbohydrate accumulation, and partitioning of ${ }^{14} \mathrm{C}$-labeled assimilates were examined 2 to 3 weeks (12-20 Oct.) into the photoperiod treatments and at the end of the treatments (2-7 Nov.). Carbon dioxide assimilation was measured on the first fully expanded leaf in the latest growth flush of each plant using an ADC Model LCA-2 infrared gas analyzer (Analytical Development Corp., Hoddesdon, U. K.) at a flow rate of $400 \mathrm{ml} \cdot \mathrm{min}^{-1}$. Measurements were taken between 1100 and 1500 HR under ambient relative humidity ( $35 \%$ to $45 \%$ ), temperature $(25$ to $31 \mathrm{C})$, and $\mathrm{PPF}>70 \Omega \mathrm{mol} \cdot \mathrm{m}^{-2} \cdot \mathrm{s}^{-1}$.

Partitioning of leaf carbohydrates between accumulated starch and soluble sugars was determined at the beginning, middle, and end of each photoperiod. Four fully expanded leaves from each of four replications were harvested at the appropriate times, freeze-dried, and ground. Tissue was extracted in boiling $80 \%$ ethanol (1: 10, w/v) to which $100 \mathrm{mg}$ of mannitol was added as an internal standard. Extracts were centrifuged, the supernatant decanted, and the pellet re-extracted twice. The combined supernatant was partitioned against chloroform, and the aqueous fraction was dried under vacuum, resuspended in water, and passed through Dowex-1 and Dowex-50 ion resins. The resulting fraction was dried under vacuum, resuspended in water, and passed through a $0.20-\mu \mathrm{m}$ filter before injection into a Bio-Rad high-performance liquid chromatography (Richmond, Calif.). Samples were analyzed for soluble sugars using a Bio-Rad HPX $87 \mathrm{C}$ cation-exchange column. The column was at $85 \mathrm{C}$, and the flow rate was $0.6 \mathrm{ml}$ water $/ \mathrm{min}$.

Leaf starch content, was determined by suspending the $80 \%$ insoluble ethanol fraction in $2.0 \mathrm{ml} \mathrm{KOH}$ and boiling for 30 min. After cooling, $\mathrm{pH}$ was adjusted to 4.5 with $400 \mathrm{\mu l}$ of 1.0 $\mathrm{m}$ acetic acid, and ${ }^{14} \mathrm{C}$-labeled sucrose was added as an internal standard. One milliliter of Rhizopus amyloglucosidase (9 $\left.\mathrm{mg} \cdot \mathrm{ml}^{-1}\right)$ in $0.2 \mathrm{~m}$ calcium acetate buffer $(\mathrm{pH} 4.5)$ was added and the samples were incubated in a shaking water bath for 24 $\mathrm{h}$ at $37 \mathrm{C}$. After incubation, sample pigment was removed by sequential addition of $50 \mathrm{mg}$ polyvinylpolypyrrolidone followed by $1 \mathrm{ml}$ Dowex-1 anion-exchange resin. After centrifugation, an aliquot was removed for determination of ${ }^{14} \mathrm{C}$ recovery, and glucose concentration was determined enzymatically (Sigma 510A diagnostic kit; Sigma, St. Louis).

To determine the extent of current assimilate mobilization from source leaves during flower bud initiation, partitioning of ${ }^{14} \mathrm{C}$-labeled photosynthate was monitored at two intervals (1214 Oct. and 2-4 Nov.) during the photoperiod treatments. Four replications of each cultivar were used at each interval. At the beginning of the photoperiod, plants were transferred to the laboratory and illuminated with 800 to $109 Q_{1} \mathrm{~mol} \cdot \mathrm{m}^{-2} \cdot \mathrm{s}^{-1} \mathrm{PPF}$ emitted from 400-W high-pressure sodium vapor lamps. Uniform shoots were selected on each plant, and the first fully expanded source leaf was enclosed in a 350-ml plastic bag. Leaves were maintained at $24 \pm 2 \mathrm{C}$. Plants were equilibrated for $2 \mathrm{~h}$ before injecting $1.85 \mathrm{MBq}{ }^{14} \mathrm{C}$-labeled $\mathrm{NaHCO}_{3}$ (specific activity $2.16 \mathrm{GBq} \cdot \mathrm{mmol}^{-1}$ ), followed by $100 \mu \mathrm{l}$ of $10 \% \mathrm{H}_{2} \mathrm{SO}_{4}$, into a shallow vial fixed to the side of the plastic bag. After 1 $\mathrm{h}$, the bags were removed and translocation allowed to continue in ambient air for $6 \mathrm{~h}$. After the translocation period, shoots were harvested and divided into individual leaves and nodes + subtending internodes, weighed, and freeze-dried. Tissue was extracted with boiling $80 \%$ ethanol, and ${ }^{14} \mathrm{C}$ content of the ethanolsoluble material was determined by liquid scintillation counting. The ${ }^{14} \mathrm{C}$-partitioning data are presented as percentage of ${ }^{14} \mathrm{C}$ translocated from the fed leaf.

\section{Results}

In both years, shortened fall photoperiods increased the number of flower buds initiated per plant in 'Beckyblue' (Table 1), but had no effect on initiation in 'Climax' (data not shown). For 'Beckyblue', initiation increased $100 \%$ under short photoperiods in 1989 and $16 \%$ in 1990 . The increase in flower bud initiation in 'Beckyblue' was accompanied by a decrease in the number of vegetative buds per plant in 1989 only.

Shortened fall photoperiods decreased the bloom period the following spring, increased the number of flower buds that opened, and increased total flower count for 'Beckyblue' (Table 2). Again, there was no effect of shortened fall photoperiods on 'Climax', except in 1990, when total flower count decreased. This decrease may reflect the combination of small, nonsignificant decreases in the number of flower buds initiated and the number of flowers per bud (data not shown) under shortened fall photoperiods.

Fruit set percentage decreased in 'Beckyblue' under shortened fall photoperiods in 1989 (Table 3) and was likely due to the increased number of pollinated flowers. Although percent fruit set decreased, the number of fruits harvested and the average fruit weight increased (Table 3). In 1990, the same number of flowers were hand-pollinated in each photoperiod treatment $(\approx 200)$ so that treatment effects on fruit set could be compared directly. In this case, there was no effect of photoperiod treatment on fruit set, number of fruits harvested, or fruit weight. There was no effect of photoperiod on these characteristics in 'Climax' in either year (data not shown).

Net $\mathrm{CO}_{2}$ assimilation increased dramatically in leaves of 'Beckyblue' that developed under short days (Table 4). This response was not seen in 'Climax' leaves early in the photoperiod treatment (20 Oct. 1989), but was manifested by the end of the treatment ( 7 Nov. 1989). In all cases, the increase in net $\mathrm{CO}_{2}$ assimilation was accompanied by an increase in stomatal conductance (Table 4).

Sucrose, glucose, and fructose were the only soluble leaf sugars detected. Glucose and fructose were invariably found in a 1:1 ratio; therefore, data are presented as total hexoses. There were no significant differences in leaf soluble sugar levels for the two sampling dates ( 3 weeks into the photoperiod treatments and at the end of the treatments); therefore, data for both dates were combined. Sucrose concentration in 'Climax' leaves increased throughout the day under natural photoperiods (from 4.7 to $7.1 \mathrm{mg} \cdot \mathrm{g}^{-1}$ dry weight) and decreased under short days (from 6.8 to $3.7 \mathrm{mg} \cdot \mathrm{g}^{-1}$ dry weight) (Fig. 1A). At the end of the respective photoperiods, 'Climax' leaves under short days contained significantly less sucrose than leaves under natural photoperiods. Leaves of 'Beckyblue', however, exhibited no differences in sucrose concentration either between photoperiod

Table 1. Daylength effect on number of flower and vegetative buds of 'Beckyblue' rabbiteye blueberry.

\begin{tabular}{|c|c|c|c|c|c|}
\hline \multirow[b]{2}{*}{ Cultivar } & \multirow[b]{2}{*}{ Daylength ${ }^{z}$} & \multicolumn{2}{|c|}{$\begin{array}{c}\text { Flower buds/ } \\
\text { plant }\end{array}$} & \multicolumn{2}{|c|}{$\begin{array}{l}\text { Vegetative } \\
\text { buds/plant }\end{array}$} \\
\hline & & 1989 & 1990 & 1989 & 1990 \\
\hline Beckyblue & $\begin{array}{l}\text { Natural } \\
\text { SD } \\
\text { Significance }\end{array}$ & $\begin{array}{c}21.9 \\
48.0 \\
* *\end{array}$ & $\begin{array}{c}183.7 \\
214.9 \\
*\end{array}$ & $\begin{array}{c}66.9 \\
46.0 \\
* *\end{array}$ & $\begin{array}{c}178.5 \\
164.2 \\
\text { NS }\end{array}$ \\
\hline
\end{tabular}

zDaylength during the 5 weeks in fall just before defoliation and chilling. Natural = decreasing daylength from 12 to $11 \mathrm{~h} ; \mathrm{SD}=$ decreasing daylength from 10 to $8 \mathrm{~h}$.

Ns, $*, * *$ Nonsignificant or significant at $P=0.10$ or 0.05 , respectively. 
Table 2. Daylength effect on bloom period, flower budbreak, and total flower number of 'Beckyblue' and 'Climax' rabbiteye blueberry.

\begin{tabular}{|c|c|c|c|c|c|c|}
\hline \multirow[b]{2}{*}{ Cultivar } & \multirow[b]{2}{*}{ Daylength ${ }^{2}$} & \multicolumn{2}{|c|}{$\begin{array}{c}\text { Bloom period } \\
\text { (days) }\end{array}$} & \multirow{2}{*}{$\begin{array}{l}\begin{array}{c}\text { Flower buds broken } \\
\text { (\% flower buds/plant) }\end{array} \\
1989 \mathrm{y}\end{array}$} & \multicolumn{2}{|c|}{ Total no. florets } \\
\hline & & 1989 & 1990 & & 1989 & 1990 \\
\hline Beckyblue & $\begin{array}{l}\text { Natural } \\
\text { SD } \\
\text { Significance }\end{array}$ & $\begin{array}{c}12.7 \\
9.0 \\
* *\end{array}$ & $\begin{array}{c}37.5 \\
32.9 \\
* *\end{array}$ & $\begin{array}{c}43.8 \\
61.7 \\
* *\end{array}$ & $\begin{array}{c}56 \\
177 \\
* *\end{array}$ & $\begin{array}{c}1016 \\
1194 \\
* *\end{array}$ \\
\hline Climax & $\begin{array}{l}\text { Natural } \\
\text { SD } \\
\text { Significance }\end{array}$ & $\begin{array}{c}13.5 \\
17.1 \\
\text { NS }\end{array}$ & $\begin{array}{c}33.9 \\
32.0 \\
\text { NS }\end{array}$ & $\begin{array}{c}23.6 \\
25.3 \\
\text { NS }\end{array}$ & $\begin{array}{c}96 \\
81 \\
\text { NS }\end{array}$ & $\begin{array}{c}1155 \\
1007 \\
* *\end{array}$ \\
\hline
\end{tabular}

${ }^{2}$ Daylength during the 5 weeks in fall just before defoliation and chilling. Natural $=$ decreasing daylength from 12 to $11 \mathrm{~h}$; SD = decreasing daylength from 10 to $8 \mathrm{~h}$. y No data for 1990 .

NS,*,**Nonsignificant or significant at $P=0.10$ or 0.05 , respectively.

Table 3. Daylength effect on fruit set, number of fruits harvested, and fruit weight of 'Beckyblue' rabbiteye blueberry.

\begin{tabular}{|c|c|c|c|c|c|c|c|}
\hline \multirow[b]{2}{*}{ Cultivar } & \multirow[b]{2}{*}{ Daylength } & \multicolumn{2}{|c|}{$\begin{array}{c}\text { Fruit } \operatorname{set}^{2} \\
(\%)\end{array}$} & \multicolumn{2}{|c|}{$\begin{array}{l}\text { No. fruit } \\
\text { harvested }\end{array}$} & \multicolumn{2}{|c|}{$\begin{array}{c}\text { Fruit wt } \\
\text { (g/berry) }\end{array}$} \\
\hline & & 1989 & 1990 & 1989 & 1990 & 1989 & 1990 \\
\hline \multirow[t]{3}{*}{ Beckyblue } & Natural & 52.5 & 44.7 & 37.0 & 94.6 & 1.5 & 2.3 \\
\hline & SD & 38.8 & 42.0 & 68.7 & 96.4 & 1.8 & 2.5 \\
\hline & Significance & $* *$ & NS & $\star \star$ & NS & $\star \star *$ & NS \\
\hline
\end{tabular}

${ }^{2}$ Arcsin transformation of the data was performed before analysis. 'Daylength during the 5 weeks in fall just before defoliation and chilling. Natural $=$ decreasing daylength from 12 to $11 \mathrm{~h}$; $\mathrm{SD}=$ decreasing daylength from 10 to $8 \mathrm{~h}$.

,*,**Nonsignificant or significantat $\mathrm{P}=0.10$ or 0.05 , respectively.

treatments or during the course of the day, averaging $6.1 \mathrm{mg} \cdot \mathrm{g}^{-1}$ dry weight. Leaf hexose concentration increased from 7.8 to $13.1 \mathrm{mg} \cdot \mathrm{g}^{-1}$ dry weight throughout the course of the day for 'Climax' under natural photoperiod, while under short photoperiods, hexose concentration was similar throughout the day, averaging $10.6 \mathrm{mg} \cdot \mathrm{g}^{-1}$ dry weight (Fig. 1B). Leaves of 'Beckyblue' had similar hexose concentrations under natural photoperiods throughout the day; however, hexose levels increased sharply from 7.5 to $21.1 \mathrm{mg} \cdot \mathrm{g}^{-1}$ dry weight throughout the day under short photoperiods (Fig. 1B).

Photoperiod effects on leaf starch concentration were consistent and dramatic. As with leaf soluble sugars, no differences in starch levels were evident for the two sampling dates, and data for both harvests were combined. For both cultivars, starch concentrations were significantly higher throughout the day under natural (averaging 46.5 and $57.7 \mathrm{mg} \cdot \mathrm{g}^{-1}$ dry weight for 'Beckyblue' and 'Climax', respectively) than under short photoperiods (20.2 and $15.9 \mathrm{mg} \cdot \mathrm{g}^{-1}$ dry weight for 'Beckyblue' and 'Climax', respectively) (Fig. 2). Within a photoperiod treatment, there were no significant differences in starch concentration throughout the day.

Translocation and partitioning patterns of ${ }^{14} \mathrm{C}$-labeled assimilates were similar for both labeling dates, so data from both times were combined. The percentage of ${ }^{14} \mathrm{C}$ translocated out of the source leaf was not affected by photoperiod for either cultivar, averaging $58 \%$ for 'Beckyblue' and 50\% for 'Climax'. There was no effect of photoperiod on the percentage of translocated ${ }^{14} \mathrm{C}$-labeled assimilates partitioned to leaves of either cultivar (data not shown). Partitioning of ${ }^{14} \mathrm{C}$-labeled assimilates to stems was similar in 'Climax' under either photoperiod, averaging $\approx 6 \%$ to $7 \%$ of the total ${ }^{14} \mathrm{C}$ translocated. In 'Beckyblue', significantly more of the translocated ${ }^{14} \mathrm{C}$-labeled assimilates were partitioned to stems under short than under natural days (4.1\% vs. $1.9 \%$, respectively).

\section{Discussion}

The increased flower bud initiation in 'Beckyblue' rabbiteye blueberry under shortened fall photoperiod was similar to that of lowbush (Hall and Ludwig, 1961) and highbush (Hall et al., 1963) blueberry. The critical daylength for initiation in both of these species is $\approx 12 \mathrm{~h}$, and the number of flower buds initiated in lowbush clones increases with decreasing daylength from 12 to $8 \mathrm{~h}$ (Hall and Ludwig, 1961). Their results are similar to those observed with 'Beckyblue', suggesting that photoperiod effects on initiation in blueberry are quantitative rather than qualitative.

Flower bud initiation in 'Climax' was not affected by the photoperiod treatments. Since photoperiods longer than $12 \mathrm{~h}$ were not used in this study, it is not known whether initiation in 'Climax' would decrease at daylengths longer than $12 \mathrm{~h}$.

Table 4. Daylength effect on net $\mathrm{CO}_{2}$ assimilation (A) and stomatal conductance (gs) in 'Beckyblue' and 'Climax' rabbiteye blueberry.

\begin{tabular}{|c|c|c|c|c|c|}
\hline \multirow[b]{2}{*}{ Cultivar } & \multirow[b]{2}{*}{ Daylength $^{\mathbf{z}}$} & \multicolumn{2}{|c|}{$\mathrm{A}\left(\mu \mathrm{mol} \mathrm{CO}_{2} / \mathrm{m}^{2} \text { per sec }\right)^{y}$} & \multicolumn{2}{|c|}{ gs $\left(\mathrm{mmol} \cdot \mathrm{m}^{-2} \cdot \mathrm{s}^{-1}\right)^{\mathrm{y}}$} \\
\hline & & 20 Oct. 1989 & 7 Nov. 1989 & 20 Oct. 1989 & 7 Nov. 1989 \\
\hline \multirow[t]{2}{*}{ Beckyblue } & Natural & $3.0 \pm 0.3$ & $5.6 \pm 1.1$ & $32 \pm 1$ & $52 \pm 12$ \\
\hline & & $6.2 \pm 0.6$ & $8.3 \pm 0.5$ & $52 \pm 8$ & $112 \pm 8$ \\
\hline \multirow[t]{2}{*}{ Climax } & Natural & $4.2 \pm 0.9$ & $5.7 \pm 0.4$ & $32 \pm 1$ & $56 \pm 8$ \\
\hline & SD & $5.3 \pm 0.6$ & $9.2 \pm 1.1$ & $36 \pm 8$ & $100 \pm 20$ \\
\hline
\end{tabular}

${ }^{2}$ Daylength during the 5 weeks in fall just before defoliation and chilling. Natural $=$ decreasing daylength from 12 to $11 \mathrm{~h} ; \mathrm{SD}=$ decreasing daylength from 10 to $8 \mathrm{~h}$.

YValues are means of four replications (two leaves/replication) \pm SE. Measurements taken from 1100 to $1500 \mathrm{HR}$ at PPF higher than $700 \mu \mathrm{mol} \cdot \mathrm{m}^{-2} \cdot \mathrm{s}^{-1}$. 


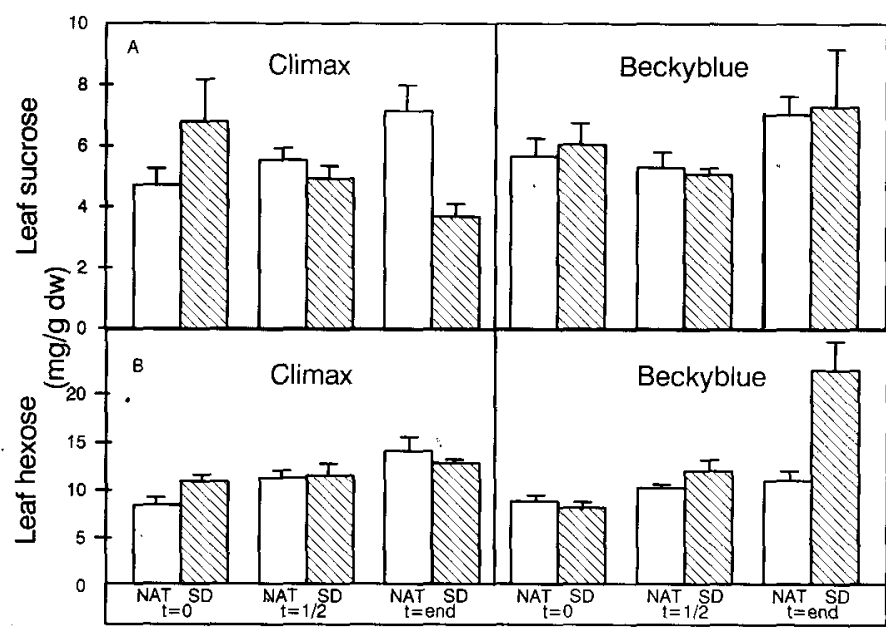

Fig. 1. Photoperiod and diurnal effects on leaf sucrose (A) and leaf hexose $(\mathbf{B})$ concentrations. NAT $=$ natural daylengths, decreasing from 12 to $11 \mathrm{~h} ; \mathrm{SD}=$ short daylengths, decreasing from 10 to 8 $h ; t=0, t=1 / 2, t=$ end represents samples taken at the beginning, middle, and end of the respective photoperiods on a given day.

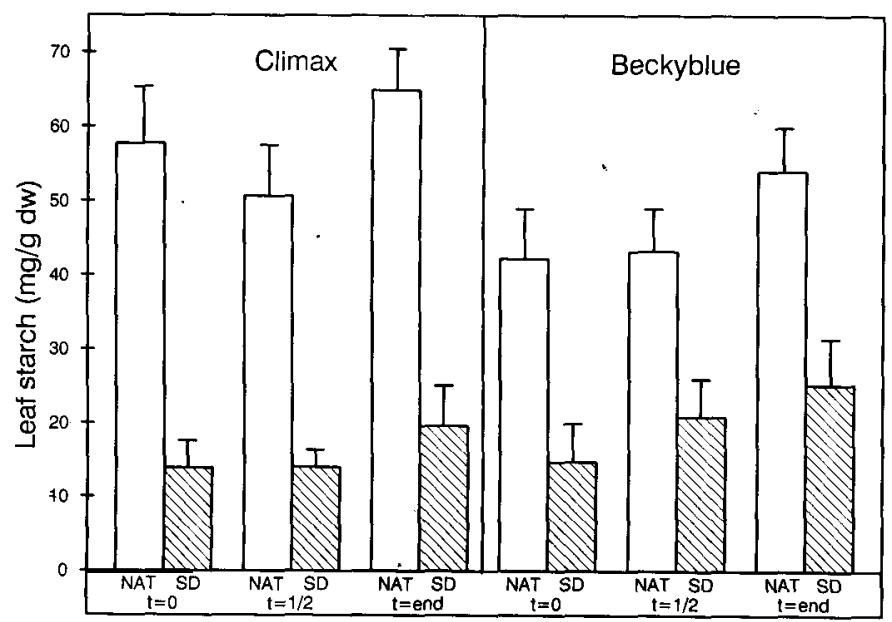

Fig. 2. Photoperiod and diurnal effects on leaf starch concentrations. NAT = natural daylengths, decreasing from 12 to $11 \mathrm{~h} ; \mathrm{SD}=$ short daylengths, decreasing from 10 to $8 \mathrm{~h} ; \mathrm{t}=0, \mathrm{t}=1 / 2, \mathrm{t}=$ end represents samples taken at the beginning, middle, and end of the respective photoperiods on a given day.

However, initiation in highbush cultivars was similar under 10and 12-h daylengths, while 14- and 16-h daylengths substantially reduced the number of flower buds initiated (Hall et al., 1963). Initiation in 'Climax' probably would also decrease at daylengths longer than $12 \mathrm{~h}$.

Shortened fall photoperiods affected several other reproductive responses in 'Beckyblue' that have not been reported for highbush or lowbush blueberries. The decrease in the length of the bloom period and the increased number of flower buds that opened suggest that synchronization of flower bud differentiation was better under short than under natural days. Additionally, the increase in fruit weight in 1989, even under conditions of a higher fruit load, suggests that cell number may have been increased by short fall photoperiods. The lack of photoperiod effect on fruit weight in 1990 may indicate that the sensitivity of certain reproductive factors to photoperiod decreases with plant age, as reported for azaleas (Pettersen, 1972) and other woody plants (Wareing, 1956).

The increase in $\mathrm{CO}_{2}$ assimilation observed in leaves that developed under short days has not been previously reported. Photoperiod had no effect on $\mathrm{CO}_{2}$ assimilation in soybean (Chatterton and Silvius, 1979), tomato (Logendra et al., 1990), or cucumber (Robbins and Pharr, 1987). Under natural temperate conditions, shortened daylengths in these crops would signal the end of the growing season and the onset of whole-plant senescence. For woody, perennial crops such as blueberry, naturally shortened photoperiods precede the onset of dormancy, and carbohydrate reserves required for dormancy and subsequent spring budbreak begin to increase (Hansen and Grauslund, 1973; Tromp, 1983; Worley, 1979). Thus, the increase in $\mathrm{CO}_{2}$ assimilation in blueberry under short days may be in response to the onset of dormancy and the initiation of carbohydrate reserve accumulation.

Assuming the differences in $\mathrm{CO}_{2}$ assimilation were manifested throughout the day and throughout the photoperiod treatments, the average amount of net carbon fixed during the daily light period by leaves of 'Beckyblue' would be higher under short than under natural photoperiods $\left(68\right.$ and $55 \mu \mathrm{g} \mathrm{C} / \mathrm{cm}^{2}$ per day, respectively). The increased carbon fixed by 'Beckyblue' leaves under short photoperiods appears to be stored as hexoses, since leaf hexose levels in 'Beckyblue' increased dramatically under short-day conditions. The decrease in leaf hexose levels between the end and the beginning of the photoperiod in this cultivar suggests that hexoses are used as carbon sources for either source leaf respiration/maintenance reactions or as a source of carbon for export to sink organs during the night. Pepper leaves also accumulate high levels of hexose under short-day conditions and appear to use this sugar pool as a carbon source throughout the dark period (Grange, 1985). Leaf hexoses do not appear to be involved in supplying carbohydrates during the night in 'Climax'. As well, the inconsistent pattern in leaf sucrose accumulation in both cultivars during the course of the photoperiods suggests that sucrose plays only a minor role in supplying carbohydrates to sink organs during the night.

Although there were consistent effects of photoperiod on leaf starch concentration, the lack of significant differences in concentration between the end of the photoperiod and the beginning suggests that leaf starch, as with soluble sugars, has only a small role in carbohydrate supply during the night. This pattern contrasts with that for tomato (Logendra et al., 1990), pepper (Grange, 1985), and soybean (Chatterton and Silvius, 1979), where leaf starch is mobilized and translocated during the night. The initiation of starch breakdown may depend on the depletion of leaf sucrose to a critical level (Grange, 1985). In blueberries, this does not appear to be the case. Possibly, woody perennials, such as blueberry, use starch stored in other plant parts (e.g., shoots, stems) to support translocation during the night.

Short days have been found to either decrease (Chatterton and Silvius, 1979; Robbins and Pharr, 1987) or have no effect (Abou-Haidar et al., 1985; Grange, 1985) on leaf export rates. Export rates in blueberry do not appear to be affected by photoperiod; however, determination of translocation using ${ }^{14} \mathrm{C}$ labeling does not indicate whether differential mobilization of reserves was occurring during the 6-h translocation period. Although leaf starch levels within a photoperiod treatment did not change during the day (Fig. 2), suggesting that differential mobilization of reserves was not occurring, there may be simultaneous starch synthesis and degradation (Fondy and Geiger, 1985), which might result in differential export of unlabeled 
starch. It is clear, however, that short days altered the partitioning of translocated assimilates in 'Beckyblue', resulting in more partitioning to stem tissue than under long days. This alteration occurred as early as 2 weeks into the photoperiod treatments, before the completion of the 5- to 6-week inductive cycle required for optimum flower bud initiation in blueberry (Hall and Ludwig, 1961). This pattern was not seen in 'Climax', where photoperiod did not affect either flower bud initiation or ${ }^{14} \mathrm{C}$ partitioning. This difference suggests that increased assimilate partitioning to nodes under short days may contribute to the observed effect of short days on initiation. High light intensity in some long-day plants can partially overcome the inhibitory effects of short days (Bodson, 1983) or enhance the promotive effect of long days (Lin and Molnar, 1983) on flower bud initiation. These authors suggest that this effect is due to an increase in carbohydrate production and allocation to the meristems. An increase in soluble carbohydrates in the apex of the long-day plant Sinapis alba appears to be a prerequisite for flower initiation (Bodson, 1977). Furthermore, floral development in tobacco explants is enhanced by oligosaccharins (Tran Thanh Van et al., 1985), and sugar-modulated gene expression has recently been reported (Sheen, 1990). These findings suggest that carbohydrates may have a specific role in the floral signal for some plants. However, the increased partitioning to stem tissue observed in blueberries may be in response to the early stages of vegetative to floral transition and may not play a role in determining flower bud number.

Short photoperiods in the fall increase leaf $\mathrm{CO}_{2}$ assimilation, current assimilate partitioning to stem tissue, and flower bud initiation and development in 'Beckyblue' rabbiteye blueberry. This effect was cultivar-specific, as carbon production, allocation, and reproductive development in 'Climax' were not affected by the photoperiods used in this experiment. The variation in responses to photoperiod within rabbiteye blueberry suggests that careful consideration must be given to cultivar selection to ensure that daylength does not limit flower bud initiation in areas of relatively low latitude.

\section{Literature Cited}

Aalders, L.E. and I.V. Hall. 1964. A comparison of flower-bud development in the lowbush blueberry, Vaccinium angustifolium Ait. under greenhouse and field conditions. Proc. Amer. Soc. Hort. Sci. 85:281-284.

Abou-Haidar, S. S., E. Miginiac, and R.M. Sachs. 1985. ${ }^{14}$ C-assimilate partitioning in photoperiodically induced seedlings of Pharbitis nil. The effect of benzvladenine. Physiol. Plant. 64:265-270.
Bodson, M. 1977. Changes in the carbohydrate content of the leaf and the apical bud of Sinapis during transition to flowering. Planta 135:1923.

Bodson, M. 1983. Effect of photoperiod and irradiance on floral development of young plants of a semi-early and a late cultivar of azalea. J. Amer. Soc. Hort. Sci. 108:382-386.

Chatterton, N.J. and J.E. Silvius. 1979. Photosynthate partitioning into starch in soybean leaves. Plant Physiol. 64:749-753.

Fondy, B.R. and D.R. Geiger. 1985. Diurnal changes in allocation of newly fixed carbon in exporting sugar beet leaves. Plant Physiol. 78:753-757.

Grange, R.I. 1985. Carbon partitioning in mature leaves of pepper. Effects of daylength. J. Expt. Bet. 36:1749-1759.

Hall, I. V., D.L. Craig, and L.E. Aalders. 1963. The effect of photoperiod on the growth and flowering of the highbush blueberry (Vaccinium corymbosum L.). Proc. Amer. Soc. Hort. Sci. 82:260263.

Hall, I.V. and R.A. Ludwig. 1961. The effects of photoperiod, temperature, and light intensity on the growth of the lowbush blueberry (Vaccinium angustifolium Ait.). Can. J. Bet. 39:1733-1739.

Hansen, P. and J. Grauslund. 1973. ${ }^{14} \mathrm{C}$-studies on apple trees. VIII. The seasonal variation and nature of reserves. Physiol. Plant. 28:2432.

Lin, W.C. and J.M. Molnar. 1983. Effect of photoperiod and high intensity supplementary lighting on flowering of Alstroemaria 'Orchid' and 'Regina'. J. Amer. Soc. Hort. Sci. 108:914-917.

Logendra, S., J.D. Putnam, and H.W. Janes. 1990. The influence of light period on carbon partitioning, translocation and growth in tomato. Sci. Hort. 42:75-83.

Ogawa, Y. and R.W. King. 1979. Indirect action of benzyladenine and other chemicals on flowering of Pharbitis nil Chois. Plant Physiol. 63:643-649.

Pettersen, H. 1972. The effect of temperature and daylength on shoot growth and bud formation in azaleas. J. Amer. Soc. Hort. Sci. 97:17-24.

Robbins, N.S. and D.M. Pharr. 1987. Regulation of photosynthetic carbon metabolism in cucumber by light intensity and photosynthetic period. Plant Physiol. 85:592-597.

Sheen, J. 1990. Metabolic repression of transcription in higher plants. Plant Cell 2:1027-1038.

Tran Thanh Van, K., P. Toubart, A. Cousson, A.G. Darvill, D.J. Collin, P. Chelf, and P. Albersheim. 1985. Manipulation of morphogenic pathways of tobacco explants by oligosaccharins. Nature (London) 314:615-617.

Tromp, J. 1983. Nutrient reserves in roots of fruit trees, in particular carbohydrates and nitrogen. Plant \& Soil 71:401-413.

Wareing, P.R. 1956. Photoperiodism in woody plants. Annu. Rev. Plant Physiol. 7:191-214.

Worley, R.E. 1979. Fall defoliation date and seasonal carbohydrate concentration of pecan wood tissue. J. Amer. Soc. Hort. Sci. 104:195199. 